\title{
The OJ/OC Program: A Non-Resident MPH Program in Medical Care Administration
}

\author{
Roy Penchansky, DBA*
}

In August of 1972 the Department of Medical Care Organization of the School of Public Health of the University of Michigan initiated a non-resident Master of Public Health Degree Program in Medical Care Administration. This program has come to be known as the OJ/OC program for On-Job and On-Campus. The first class of the $O J / O C$ program graduated in August of 1974. There was great demand from potential students, and since the first program was proceeding satisfactorily, a second class was matriculated in the fall of 1973. These first programs were viewed as experimental and were approved by the faculty on a one-time basis. In January of 1975, after the curriculum committee of the School had evaluated the program, the faculty voted to make the $\mathrm{OJ} / \mathrm{OC}$ program a permanent feature of the School. A third class began in April 1975. There are expectations that the OJ/OC structure will be used by other programs in the School.

This report will (a) describe the program structure and operating procedures, (b) describe the background to the development of the $\mathrm{OJ} / \mathrm{OC}$ program including its objectives, and (c) discuss some of the key aspects of program structure and other factors that appear to effect the performance of the program. This report focuses on educational program structure rather than on specific content. Only general material on course content and sequencing, and the rationale for these will be presented. The relationship of the type and level of education desired to the program structure will be noted recurringly.

The report is presented in terms of "we" and "our," referring primarily to the faculty of the Department of Medical Care Organization, but also including numerous other faculty members and persons who have contributed their ideas and effort to the OJ/OC program. The objective is to clearly indicate the wide range of resources and support involved in designing and administering the program. While an attempt has been made to accurately represent the views of those most concerned with the program, the judgments are the responsibility of the author.

\footnotetext{
-Dr. Penchansky is Professor of Medical Care Administration and Director of the OJOC Program (1972-1975), at the School of Public Health, University of Michigan, Ann Arbor, MI 48104.
} 


\section{Program Description}

Each program is composed of 24, four-day class sessions which are held monthly. Forty-six credits of course work, earned over the two years, are presented with a classroom-hour to course-credit ratio of slightly more than 13 to 1 . Each session is conducted from Thursday through Sunday inclusive, for 26 to 28 hours of class per month.

The participants are generally from the East Coast and northern Midwest sections of the country. All candidates must be employed in a medical care position related to ambulatory care delivery programs. While the students in the first class averaged seven years of relevant work experience, at least three years of such experience is required for admission. An age requirement of 27 years is also applied to insure some similarity in general experience. The first class averaged 38 years of age on admission, the second, 35 .

The experience requirement lets us assume, meaningfully, that participants generally understand the field, basic financing programs, current issues, and much of the terminology. This permits the faculty to cursorily present or even exclude the basics covered in residential courses, which saves course time for the extensive discussion required in dealing with issues these students raise. The job requirement also insures that the students will have a "laboratory" in which to carry out course assignments. The ability to "try things," to do minor studies, collect data, and understand the actual application of ideas is an important dimension of the program. It generates richer classroom discussion than is usual in residential programs and encourages integration of theory and practice.

The positions held by students must generally be administrative; a full-time clinician - whether nurse, physician or dentist - would not be eligible, while a medical or dental director of a neighborhood health center (NHC) or hospital outpatient department (OPD), or the nursing director of a visiting nurse service would. The position level required depends on the scale of the agency. The assistant administrator who is responsible for the OPD of a large hospital probably would be eligible, while the assistant administrator of a small NHC probably would not. Generally, participants must be in the top two levels of their organization, unless it is a large one.

It is not necessary to have already earned a bachelor's degree to enroll in the program; in both the first and third classes there were two such persons. We do require two years of college level work, or the equivalent, and extensive and progressive experience including a top level administrative position. One of the two persons in the first class without a prior degree completed the program successfully and received an $\mathrm{MPH}$ degree.

Between sessions the students are expected to prepare for class by 
doing assigned reading or carrying out work-related projects. In courses demanding monthly projects, the work may be mailed to the faculty a few days before the session to permit them to review it before classes begin. Because the students have no access to a library, they are given most of the reading material.

At any one time, we usually offer four courses with each course usually meeting for six hours of class per month. The few extra hours each month are employed to introduce a new course or for a special class topic.

Faculty find it difficult to teach more than six hours in a four-day period given their other assignments and class preparation time, and students seem overburdened with more than four simultaneous courses. These constraints and those imposed by transportation costs, as well as the limit on consecutive days that participants can leave their work and the amount of time they can effectively function in class in four days, lead us to conclude that a four-day session of about 26-27 hours with four courses is optimum.

During the first program we usually scheduled an outside speaker for an evening session to expose the $\mathrm{OJ} / O \mathrm{OC}$ students to additional ideas and key persons in the field. We also invited the residential students, hoping to stimulate interaction between the two groups. In the second program we increased the class hours per month because the faculty felt they had had inadequate class time to cover the content desired, and we reduced the evening sessions with outside speakers.

Courses given in the second OJ/OC class and the approximate credits for each course are listed below. Since we do not have to schedule courses during fixed semesters or for set hours and the course content is adjusted to the specific needs of the students, our courses sometimes have half-credit value. The list reflects the general order of presentation. It should be remembered that four courses are usually in progress at any one time.

Students can exempt a course on the basis of prior experience or training and take an individual study course as a substitute. Few have elected to do so, in part because a course in an area with which they are familiar provides a "breather" (Figure 1).

The managerial accounting and organizational behavior courses should have come earlier in the sequence and will in the future; at the least, they should precede the Operations Research and Ambulatory Care Programs courses.

The first class began with 35 students. Two people withdrew, one of these for academic reasons. Two participants were not able to receive a degree because of poor academic performance, and three people are currently completing overdue work projects. The death of two students during the first class was very upsetting to us all because of the close 
COURSE

FIGURE 1

Statistics

CREDITS

Epidemiology

Medical Care Organization and

Administration

Economics and Health Economics

Health Behavior

Demography

Medical Care Law

Operations Research

Organization and Management of

Ambulatory Care Programs

$\begin{array}{r}3 \\ 3 \\ 3 \\ 2 \\ 1 \\ 4 \\ 5 \\ \hline 46\end{array}$

* The Health System Analysis covers integrative work projects, about 15 case studies on integrative policy analysis, a series of classes and a project on family planning, and a series of classes on systems analysis (resource allocation tech. niques). This course spans most of the two years with much of it concentrated in the last seven months.

ties that had developed among the students and faculty members. In OJ/OC II we started with 32 students, we terminated a few early in the program for academic reasons, and one left for health reasons. There remain 27 participants, all of whom are current in their work, and we expect at least 25 to complete the program in August 1975.

We don't know how to evaluate the success/failure rates. The dropout and failure rates in the two OJ/OC classes have been higher than in our resident programs. But for several reasons this doesn't discourage us. First, we accept more academic risks in the OJ/OC program; that is, persons who went to school a longer time ago, persons who may have had poor academic experience but good job experience since, and a number of people who have no bachelor's degree. Given these factors, we expect losses, but more importantly, we secure many excellent students whom we would miss by employing traditional admission standards. Further, we cannot readily estimate the academic potential of a person who attended school twenty years ago, or who may have majored in music or social work. Another reason for the higher loss rate may well be more difficult courses than exist on campus, in the sense that no electives exist and the students 
take all the "tougher and/or quantitative" courses. The demands of employment probably also contribute to the loss rates.

Basically, if out of 30 to 35 admissions we can graduate 25 good students to whose performance in the field we have made a significant contribution, and who could not have otherwise received this education, then we are satisfied with the achievement from the resources committed. While we are concerned with losing students, our more critical concern is with insuring every student the support services and atmosphere essential for success if they have the innate ability and willingness to apply themselves.

At one level of analysis the issue is not whether this OJ/OC approach is useful for those who cannot come to the campus, but whether, in the long run, such an approach with its requirement of some experience, of each student having a "laboratory," and its emphasis on integration of education and work may be more effective for education of all future health administrators than is the traditional educational approach.

\section{Background}

A number of concerns of our faculty and developments in our residential master's degree program provides the backdrop for the specific events leading to the development of the $\mathrm{OJ} / \mathrm{OC}$ program. During the period roughly covering 1968 to 1972 , much of the effort of the Health Services Administration faculty was directed at analyzing the expected programs and agencies in health care, the roles of the administrators in these, the skills and knowledge such administrators would need, and the means of education for these skills and knowledge. This analysis led to extensive developments in our residential programs, some of which increased the need for a new program but which also made it easier to arrange the courses for OJ/OC. Had our programs not been relatively up to date and progressive, our $\mathrm{OJ} / \mathrm{OC}$ efforts would not have been possible or would not have been as successful.

The 12-month, 36-credit residential MPH program that existed in 1968 was inadequate; we could not even conceive of a 9-month, 30. credit MPH program as employed by some schools. We had expanded the program content in economics, statistics, and administrative technology as well as providing more specialized course work in medical care. Increasingly four to five terms of residency (16 to 20 months) with 48 to 60 credits of course work were required.

There had been a precedent for some health agencies, especially public agencies, to provide year-long leaves with economic support for employees to obtain advanced education. But it was very difficult to arrange longer academic leaves to fit our longer program. While we provided better education through the more technical and lengthy program and educated many more younger persons for the field, we 
worried that we might be reducing the potential of the older person, already in the field, to return for advanced education.

Also, as more students entered our program with little or no health experience, the curriculum changed subtly, making it difficult to accommodate the experienced student who needed less descriptive material but greater facility with quantitative tools.

We felt that a large audience of persons working in medical care administration could make excellent use of an advanced educational process, but could not be accommodated under resident programs. Of particular concern was the health professional in an executive position, especially the physician and dentist whose career evolved into medical care administration from clinical practice. These people were usually not in a position to return to campus because of family, financial, and/or job commitments.

As organized health care delivery programs increased, concern with the operations of the programs and for the programs' directors, many of whom were clinicians, grew. While public health/medical care educational programs provided a low level of technological content, little was offered to the well-trained clinicians who were willing to educate themselves on medical care matters. With economic, statistical, and management approaches being applied to health care programming, self-education became more and more difficult for persons without formal training in these subjects. The advent of the Neighborhood Health Center movement added a further dimension to our concerns about unmet educational need; increasing numbers of minority group members, whose opportunities for education had been and continued to be severely handicapped, worked in the field. It was with these concerns for the needed education of persons in the field that a series of specific events led to the design of the OJ/OC program.

In 1969, our department undertook for the Office of Health Affairs of the Office of Economic Opportunity an educational program for senior administrative staff members of neighborhood health centers. During the following two years, we offered a series of workshops aimed at increasing the skills of the persons responsible for directing NHCs in identification and definition of problems, problem analysis, decision making and evaluation, program implementation, etc., within the context of their programs.

This project had important consequences for the development of the $\mathrm{OJ} / \mathrm{OC}$ program; it helped us define the potential audience for an offcampus program in terms of numbers, educational needs, and job measures. It helped us anticipate problems we would encounter in having working people in an educational program; it helped us increase our knowledge about neighborhood health centers and about the knowledge and skills demanded of administrators of these programs. It provided us with an advisory committee, many of whose 
members made suggestions for the OJ/OC program design and furnished various types of support. This committee consisted of $\mathrm{Mr}$. Clifford Cole, Mr. Robert Council, Dr. Leslie Falk, Mr. Richard Feise, Mr. Bernard Karshmer, Dr. William Lloyd, Dr. Samuel Rogers, and Dr. Kenneth Woodward.

If a nondegree, continuing education program could have met our objectives and those of OEO for the education of NHC staffs, we probably would not have gone to a degree format, as we were not initially prejudiced toward degree programs. OEO and $\mathrm{HEW}$ were concerned with the administration of the NHC programs they were funding. Many of the administrators came from the community and had little formal college education. Others, while having formal education in administration, for example, had little health care expertise, and many of the directors of the clinical services had no administrative experience or expertise.

Three-day workshops were presented every three months for about two years. The workshops were presented near and in cooperation with a neighborhood health center with that center becoming a case study or laboratory for the workshop. The focus was on "how one approaches certain of the key program areas," with each workshop having a different program area - control of clinical services or establishment of program priorities. There was a strong action orientation. Case studies were developed in neighborhood health centers on the relevant subjects. Each workshop covered a range of related activities; faculty led discussion and lectures on the topic; staff of the local health center presented their approach to the topic or issue; participants discussed one or two case studies that related to the topic; and, after visits and interviews at the health center, group evaluation and reporting on the performance of the local health center in regard to the subject took place. The participants, usually about 35 people, were sent materials to prepare in advance.

We concluded that these workshops were not effective. The reason we present these details is to show that the lack of effectiveness was not generally attributable to the workshop programs themselves. The workshop programs were well designed and presented, but the overall program format was not useful in developing basic approaches (ways of thinking) to program and management problems. Periodic, nondegree continuing education might be useful for communicating specific information, say, about new laws to persons who appreciate their need to know this information, or to provide skill training on specific tools or techniques to persons who already have basic skills. However, this format is of little use in efforts that require longer term input, intend to develop new skills, challenge approaches to thinking, are not immediately job related, or require independent preparation. Our experience led us to conclude that, even if well done, the 
continuing education workshop format could not be effective for the types of fundamental education in economics, statistics, accounting, and management logic, for example, that we defined as necessary.

From our evaluation of this experience evolved the idea of presenting a non-resident master's degree program. Anticipating that the staffs of OEO Neighborhood Health Centers would be a major audience for the program, we approached OEO for support and received a positive response. However, OEO also wished to see other experimental programs initiated and felt that the National Association of Neighborhood Health Centers (NANHC) should have a key role in this educational effort. OEO knew that the NANHC was interested in promoting educational programs for the staffs of their member organizations and requested that we work with the NANHC to develop a number of non-resident degree programs around the country that would be worthy of OEO funding.

The NANHC, a number of whose leaders were on our advisory committee for the NHC workshops, sponsored a series of meetings to bring together representatives of educational institutions for discussion of educational needs and potential programs. The outcome of the process was a grant to the NANHC from OEO to fund the OJ/OC program and a program at the School of Public Administration of the University of Southern California. In each of the first two OJ/OC classes, 15 of the students were selected by the NANHC for support.

\section{DISCUSSION}

This discussion will focus on the factors influencing program performance, the performance of the students, the structure of the program and other possible structures, integration among courses and with the students' work, plans for the future and program economics.

\section{Program Performance}

While the structure of the program may be the easiest aspect to describe and is the unusual feature of this program, several other factors are probably more critical in determining program performance.

First, we received strong faculty support. Their cooperation, eagerness to experiment, acceptance of weekend hours and willingness to adjust courses to the specific needs of the students provided essential flexibility. Efforts to alter courses from their on-campus version to satisfy new needs generally succeeded, as did those to revise the second program on the basis of our experience with the first. The success of the program cannot be separated from the quality and attitude of the faculty.

Second, we had excellent students. For the most part, the students 
were bright, mature, sophisticated, experienced, and well motivated. With improvements in the design and presentation of the second program thought to be a major contributing factor, the $\mathrm{OJ} / \mathrm{OC}$ II student work level and performance was excellent. A strong sense of esprit de corps developed in this class and nurtured an ethic of hard work, open discussion and good humor. Our evaluation of the first class and student response to it led in part to the changes that seemingly influenced student motivation, making the second class more successful.

We wish to note, too, that our surroundings enhanced our prospects for success. We had a well-equipped classroom that, because of its semi-circular layout, air conditioning, tables, swivel chairs, coffee pot and decor, facilitated discussion among 30-35 people and provided an atmosphere in which an adult could be comfortable and attentive for the eight hours of class in a day.

\section{Performance Levels}

Students' performance and what they derive from the program are the critical issues. How much time can even the most diligent student spend during the month? What work load becomes demoralizing because its completion is impossible?

First, these students are busy with major responsibilities and great demands on their time. Unless very specific work guidelines and performance measures are applied, the outside pressures will hinder or halt academic work. This comment in no way reflects negatively on the students; it is only to say that if one plans to enroll high-level administrators in any academic program, one must anticipate the great pressure on their time. Reasonable work levels must be set, and assignment deadlines must be firm. Two hours of out-of-class work per hour of class is probably the outside limit. On this basis a student in the three weeks between sessions will work about 50 hours. When one remembers that these are working people, most of whom have families, it's clear that finding 16 to 17 hours in a week to do "schoolwork" is no easy task, especially for a hundred consecutive weeks. Under such conditions, many small projects, many milestones, and a strict adherence to deadlines are critical to defining standards and to providing the measures of success by which to sustain motivation in the face of two years of overwork.

We have encountered one major problem to date: we did not get the performance in the OJ/OC I class that was possible given the ability and potential of the students. At least in part, this was due to a few courses being below the quality necessary and to our being far too flexible with standards and evaluation. We were too flexible, forgetting that while the students were bright, mature, and motivated, they labored under heavy job pressures and, generally speaking, would 
apply only the time required. We did not require enough. During the second class, inadequate courses were few, and we better communicated our standards and maintained them. As part of this, we used more in-class quizzes and examinations. A clear relationship existed between the quality of our presentations, our ability to apply tough standards, and the student's pride in the program with its motivational effect on work and standards.

A major potential problem is that we may not be able to continue to recruit a student body of a caliber equal to that of the initial classes, and therefore, we may have set standards that cannot be maintained over the long run.

A second problem we have experienced is a lack of basic mathematical skills on the part of some students and the difficulty of tutoring them in a program like ours. A contributing problem is that by the time we become aware of the students' weaknesses in fundamental skills for courses such as statistics and economics, they have fallen far behind. We have provided tutorial assistance during the weekends, but since time for such help is severely limited, we have suggested to students that they obtain assistance in their own communities.

To prevent this problem from arising in the future, we instituted for the third class a pre-enrollment, mathematical skills workshop in a community convenient to persons who are admitted to the program. The plan is to provide self-evaluation tests for students who can then, depending on their performance, attend one or two one and a half to two-day workshops on relevant mathematics. This work should lead directly into the statistics course.

\section{Program Structure}

The OJ/OC program, as noted, has operated each month for four days. This schedule influences students' preparation, travel costs, and time away from work. It also touches upon such teaching concerns as the need to bridge the material from month to month, ease of integrating course material with work, and types of assignments possible.

Some non-resident programs are following the intensive semester concept in which the student comes to campus for about a two-week period to complete one course. We reviewed this approach and decided it was useful only when courses were very general and required limited hours. If a course deals with material of any complexity, the student cannot prepare for more than the first few hours of class. Moreover, if a course requires, say, 40 hours of class, it would be nearly impossible for student and faculty to prepare for this much class time in eight or ten consecutive days. Furthermore, there seems to be little time to digest the material or do work-related problems. 
We also wonder if administrators can as easily leave their position for four or five two-week periods per year as they can for two or two and a half working days per month. To complete our program on an intensive semester basis would require about fifteen, two-week sessions. While there are advantages to the intensive semester in reduced travel cost and the student's ability to use on-campus facilities such as the library, we do not think the approach suits a program covering the type and level of material essential to the educational needs of the high-level, employed administrators.

In the first class, we began the program with a two-week session. The point of having a longer session was to give the students an extended period away from work in which they could "get used to hitting the books." Given that we felt a need to cover a large amount of material in these two weeks and that there seemed to be great tension among the students during this initial period, the experience was exhausting and we could not sustain a high work level. While perhaps it is useful to incorporate a few longer sessions - especially when the students are engaged in the integrated field project discussed below - long, intensive periods as a regular approach appear inadequate. This experience reinforced our view that the intensive semester structure would not be useful for us. If the students lived closer, within a hundred miles, for example, a format comprising 15 hours of class over Friday and Saturday every other week might well be preferable to our current format.

\section{Integration of Educational Process}

Integration of courses and of the academic program and the student's job, while attempted with some apparent success, needs even more effort and will be a focus of attention in OJ/OC III.

As one means of better integration, short, monthly work projects in applying course material were substituted for term papers in several courses for OJ/OC II. We probably still are making inadequate use of each student's "laboratory" by continuing to rely on some of the old educational tools such as term papers, when we could be more creative in developing work-related projects.

There are several integrative activities. During the first year, we have an exercise devoted to analysis of issues in screening for cervical cancer as seen from the differing perspectives of faculty in epidemiology, statistics, medical care administration and health economics. This exercise is simultaneous with courses on these topics. Another project seeks to integrate these courses by having the students see whether the class material has meaning in their work setting and by learning to employ some of the techniques taught. The students, over a period of three to four months, work through an assignment in 
which, for a given diagnosis or condition, they measure its incidence and prevalence and compare it to available epidemiological data, analyze service use rates, determine if use rates are influenced by patient, provider or system characteristics, determine whether patient and provider characteristics are related, and do the statistical tests for such analysis. This exercise also forces students to employ their medical record and data systems. The project for the Health Behavior course follows up on this activity, dealing with health education experiments to influence the utilization patterns found.

Toward the end of the program the students work on an actual problem in an actual setting. The problems sought are complex, multifaceted and ill defined; they require the use of concepts and skills covered in numerous courses. The students participate in negotiating the terms of the project with the agency personnel and in deciding on the means to analyze the problem, the information needed, and the organization of the work. After classroom discussion of the study plan, the students undertake data collection in the field, carry out the analysis, and prepare a report. Finally they present their conclusions to the agency. For this work the students divide into teams, with each team working on the same project over a three-tofour month period.

For OJ/OC I, we were fortunate in obtaining the cooperation of the staff of the New York State Medicaid Program in a project in which the students were faced with the problem of the means to evaluate New York State's Early Preventive Screening, Diagnosis and Treatment (EPSDT) Program.

\section{Planned Changes}

What are our plans for the future? Between OJ/OC I and II we focused primarily on the quality of course presentation and student performance. Even though most courses were satisfactory, efforts were made to better integrate these courses with the students' work settings and to provide bridges from month to month in the classroom presentations. Future changes will focus on improving basic mathematical skills of the students, further integrating courses and attempting "more innovative" teaching techniques in the basic skills courses.

While we may have been innovative in our program structure, our use of case studies, and our integrative work projects, we have made only limited use of potentially valuable self-teaching techniques for basic knowledge and skill subjects such as statistics, accounting, and economics. In OJ/OC II a programmed text was used, in an apparently effective way, to provide the basic accounting sections of the managerial accounting course. Plans are now being made to use a 
programmed text, with supportive classroom sessions, for the statistics course. We anticipate integrating this work with the pre-program mathematical skills workshop noted earlier. In a non-resident program, self-instruction techniques that the student can work with at home would seem to have great potential.

\section{Program Economics}

What are the economics of an OJ/OC type program as compared to a residential program? There are a number of relevant issues: the cost of producing the program to the university and the effect on the institution's economic position, the cost to the participants, and related issues of possible support for the university or students. If one assumes that the cost of producing the program is the same for both, then the critical issue is the cost to the student or funding agency and obtaining funding agency support. In fact, even with the cost of reproducing materials provided to each student, the costs of adding a non-residential program to a residential one should make for a lower marginal cost. We assume that tuition cost will be the same under both programs; in fact, because of the support we have received for the OJ/OC program the tuition level has been set at about 60 percent of the comparable resident tuition. Adding a non-resident degre $\epsilon$ program to a resident degree program and lowering average cost would, if the tuition level is the same, improve the financial position of an institution (at least in the sense of lowering average deficits).

Most of the participants in our OJ/OC program could not come to a residential program. They cannot afford to leave their work, thereby giving up a salary of $\$ 15,000-\$ 30,000$ a year and having to move their families to Ann Arbor and back to their work site at some considerable cost. Therefore, the issue of relative cost to the student between resident and non-resident instruction may be a moot one. It is clear, however, that the cost of traveling to and staying in Ann Arbor each month, which is between $\$ 2,500$ and $\$ 4,500$ per year for most participants, doesn't approach the cost of losing a salary and moving to and from Ann Arbor. Further, students can reasonably consider the expenses of participating in the $\mathrm{OJ} / \mathrm{OC}$ program a deductible educational expense for tax purposes, while this might not be the case if they left their work and were in a residential program.

It seems clear that an employer can more readily assist in meeting educational costs under the conditions existing with the $\mathrm{OJ} / \mathrm{OC}$ program where there is no cost for support for basic living expenses and the employee remains at work than for a residential program where there are basic living expenses and the employee may have to be replaced. Many institutions are willing to provide the employees with leave time for the days each month they are in Ann Arbor and to share the cost of the program with the participant. 


\section{SUMMARY AND CONCLUSIONS}

I have attempted to provide a brief description of our program format, some historical background to elucidate our objectives and the evolution of our approach to this program, and our initial observations on program performance. We hesitate to draw generalizations from our experience because it is too recent, meager, and idiosyncratic. There are, however, a number of areas where some conclusions would seem to be reasonable at this time.

In an educational program attempting to provide basic skills or new approaches to thinking about subjects, the periodic, noncredit workshop is of limited use.

In an educational program attempting to provide a high level of sophistication in subject matter which requires extensive reading and individual study or attempting to integrate the educational process with work projects, a format involving more and shorter sessions is preferable to one involving fewer and longer sessions.

An educational program for persons actively employed and with considerable job pressures requires for adequate performance that faculty clearly specify and strictly adhere to program requirements and performance standards. Many benchmarks to define and measure progress seem useful.

The level of participant performance in non-resident degree programs with a format such as ours can be identical to - or even superior to - the performance in resident programs.

Our conclusion is that the OJ/OC program is a success on several counts: we have had excellent students whom we could not have reached with a residential program; these students report that our program has been valuable to them and their evaluations of most courses have demonstrated the students' high regard. The students demand quality performance from the faculty and bring much information to the class; both of these stimulate the faculty which in turn improves all our courses. The two phenomena most indicative of the program's value are: first, the faculty, who already have an excessive work load and who receive no additional compensation for teaching in $\mathrm{OJ} / \mathrm{OC}$, have been willing to shoulder an extra burden to continue the program; and second, the students and graduates actively promote the program, supplying us with the majority of new applicants. 